\title{
Stable Isotope Characteristics for Precipitation Events and Their Responses to Moisture and Environmental Changes During the Summer Monsoon Period in Southwestern China
}

\author{
Chengcheng $\mathrm{Xia}^{1,2}$, Guodong Liu ${ }^{1,2 *}$, Ke Chen ${ }^{2}$, Yue $\mathrm{Hu}^{2}$, Jing Zhou ${ }^{2}$, \\ Yaping Liu ${ }^{2}$, Jie $\mathrm{Mei}^{2}$ \\ ${ }^{1}$ State Key laboratory of Hydraulics and Mountain River Engineering, Sichuan University, Chengdu, China \\ ${ }^{2}$ College of Water Resource and Hydropower, Sichuan University, Chengdu, China
}

Received: 6 April 2019

Accepted: 2 July 2019

\begin{abstract}
Samples of hydrogen and oxygen stable isotopes in precipitation collected and analyzed during the summer monsoon in 2017 and 2018 in Chengdu are reported in this paper. Increasing (decreasing) trends of isotope values ( $\delta \mathrm{D}$ and $\delta^{18} \mathrm{O}$ ) occur from May to June (September to October), and the valleys occur from July to August. The correlation between $\delta \mathrm{D}$ and $\delta^{18} \mathrm{O}$ for both precipitation events and monthly average precipitation is significant, with high $\mathrm{R}^{2}$ values $(\geq 0.98)$. The differences in regression lines may be due to the comprehensive influence of moisture sources, transport path and sub-cloud processes. Combining the d-excess values of precipitation and air mass trajectories generated by the HYSPLIT model, precipitation with a low (high) d-excess value and a more (less) negative $\delta^{18} \mathrm{O}$ corresponds to moisture from ocean (inland) sources. The $\delta^{18} \mathrm{O}$-temperature $(\mathrm{T})$ and $\delta^{18} \mathrm{O}$-precipitation $(\mathrm{P})$ correlations are not significant and vary greatly among different periods, which may be attributed to the mutual masking of different effects and the influence of atmospheric circulation processes. The results imply that the negative values in biological and geological proxies may be related to warmer climate, higher precipitation and a larger contribution of oceanic monsoon precipitation, but cannot indicate the changes in temperature and precipitation quantifiably.
\end{abstract}

Keywords: D-excess, moisture source, paleoclimate, stable isotopes, subtropical monsoon climate

*e-mail: 415145321@qq.com 


\section{Introduction}

Differences in the composition characteristics and evolution rules owing to the occurrence of fractionation, hydrogen, and oxygen stable isotopes in natural water present obvious spatial and temporal changes. Such differences create a unique "fingerprint" of the water body. Although the ratio of stable isotopes in water is small, it is sensitive to environmental change and is widely used in hydrology, meteorology, ecology, and paleoclimatology [1-4]. In the study of the modern water cycle, stable isotope technology plays an important role in tracing the moisture sources of atmospheric precipitation, determining the sources of rivers and lakes, distinguishing groundwater recharge sources, indicating evapotranspiration, and separating runoffs [5-9].

As the primary step in the water cycle, precipitation is an important source of surface- and groundwater. Variation in the stable isotopic composition of precipitation is affected by climate change and is closely related to regional geographical features and meteorological conditions. It can be used to reflect changes of the meteorological conditions of the water vapor source, air mass migration trajectory, local evapotranspiration conditions, and large-scale weather patterns $[4,10]$. Some important biological and geological proxies that reflect paleoclimate such as $\delta \mathrm{D}$ and $\delta^{18} \mathrm{O}$ in stalagmites, tree rings, and ice cores; $\delta \mathrm{D}$ in some plant-derived sediments; and $\delta^{18} \mathrm{O}$ in cave speleothems are often associated with precipitation [11-15]. Therefore, in the study of paleoclimatic change, it is important to understand the responses of regional precipitation isotopes to atmospheric processes. International research on stable isotopes in precipitation began in the 1950s. The International Atomic Energy Agency (IAEA) and the World Meteorological Organization (WMO) jointly launched the Global Precipitation Isotope Network (GNIP) in 1958, which became operational in 1961. In 1961, Craig analyzed the hydrogen and oxygen stable isotope composition of different water bodies worldwide and developed the global meteoric water line (GMWL) equation, which has been internationally recognized and widely used [16]. In 1964, Dansgaard proposed four influencing factors for stable isotopes in global precipitation: temperature, precipitation, elevation, and distance from the sea. The isotopic composition is related mainly to the temperature effect in the middle and high latitudes and precipitation effects in the tropical and low-latitude regions [17]. Since then, researchers have identified influencing factors for the isotopic composition of precipitation at different spatial scales based on the GNIP dataset and monitoring data collected worldwide. For example, a significant negative correlation exists between $\delta^{18} \mathrm{O}$ in precipitation and latitude and altitude in China, especially in the Qinghai-Tibet Plateau [18]. In arid climate regions, rain droplets undergo strong sub-cloud secondary evaporation when landing from the cloud base, resulting in variations in isotopic composition and deviation of the local meteoric water line (LMWL) from the GMWL [19-22]. A study conducted in the leeward side of the Himalayas showed that factors such as temperature, vapor pressure, cloud-to-ground distance, and isotopic concentrations of water vapor in the external environment significantly altered the isotopic composition of precipitation. The slope and intercept of LMWL are 7.2 and -15.8, respectively, which are much smaller than those of GMWL because of the strong effect of sub-cloud evaporation [23]. The synoptic processes affect the isotope composition of precipitation by changing the isotope fractionation in atmospheric water vapor. For example, the occurrence of heavy rain can quickly remove heavy isotopes from atmospheric water vapor, resulting in the depletion of these isotopes in the residual water vapor [24].

Monsoon circulation, an important carrier of water vapor transport, affects precipitation by restricting the distribution of large-scale water vapor transport fields and the status of the water vapor budget $[25,26]$. In a monsoon climate zone, obvious seasonal differences occur in the moisture sources owing to the alternating control of different monsoon systems. In addition, the formation mechanism of stable isotopes in precipitation is complicated. The composition of such isotopes in a monsoon region is determined mainly by three factors: (1) meteorological conditions in the moisture source, which determine the initial isotopic composition of the water vapor; (2) the transport processes of water vapor, which determine the degree of fractionation of isotopes in the air mass; and (3) external environmental factors during precipitation, which determine the fractionation and exchange of stable isotopes in the formation and land processes of raindrops. Therefore, in addition to the well-known temperature and precipitation effects, different moisture sources and transport processes in a monsoon climate zone have an important impact on the composition of precipitation isotopes. Owing to significant seasonal variation in the dominant air masses, the environmental factors affecting the stable isotope composition in a monsoon region vary with the climate system. For example, as the moisture source changes, the temperature is directly proportional in some months and inversely proportional in others, which is significantly different from that occurring in non-monsoon zones [27-30]. Evaluation of the isotope data can provide specific information on the formation mechanism of monsoon precipitation and the sources of water, thus helping to understand the processes of climate change. In various regions of the world, many studies have been conducted on the relationship between precipitation isotopes and monsoon activities. In the tropical monsoon region of Asia, the composition of precipitation isotopes is strongly correlated with cloud-base elevation and the transport path of the dominant air masses [31]. A study that collected isotope samples from 2007 to 2009 in southern China showed that precipitation 
isotopes and water vapor sources present obvious seasonal changes on annual and inter-annual scales under the effect of the monsoon system. The annual average d-excess value varies from 9.7 in 2008 to 16.6 in 2009. The water vapor of winter and spring precipitation originates mainly from evaporation of the adjacent oceans and local water bodies, with positive $\delta \mathrm{D}, \delta^{18} \mathrm{O}$ and $d$ values; however, water vapor from the distant ocean is the main contributor to summer precipitation, with negative $\delta \mathrm{D}, \delta^{18} \mathrm{O}$ and d values [32]. An investigation in northeastern China used stable isotopes to prove that the summer precipitation in this area originates from the East Asian monsoon, whereas the winter precipitation is affected by Eurasian atmospheric circulation in the mid-high latitudes [33]. Recently, a study in Hemuqiao watershed compared the d-excess and LMWL of different rain types (typhoon and plum rain). The range of d-excess is $4.06-17.98 \%$ for typhoon events and $3.45-19.12 \%$ for plum rain events, and the slope of LMWL is 7.52 for typhoon events and 6.17 for plum rain events, respectively, reflecting the isotopic difference between moisture from marine origin (typhoon events) and near-source evaporation (plum rain) [34].

Located in the Chengdu Plain in southwestern China, Chengdu has a subtropical monsoon climate, with the summer monsoon beginning to form in May and fading in late September or October [35]. During the summer monsoon, Chengdu is alternately controlled by the East Asian monsoon and the Indian monsoon. The change and instability of the dominant monsoon leads to uncertainty of the moisture source, resulting in a complex isotope composition in precipitation in this region. Located in the transition zone from the Sichuan Basin to the western Sichuan Plateau, Chengdu is an important research area for hydrology, ecology, geography, and meteorology. However, only very limited monthly precipitation data are available from the GNIP dataset in this area, and the isotope records for independent precipitation events are lacking. The isotope data of GNIP with monthly precision cannot describe the changes in stable isotopes in the synoptic scale or the impacts of meteorological events such as typhoons, cyclones, and storms during summer monsoon activity on the precipitation isotopes. Therefore, we monitored event-based precipitation stable isotope data and recorded the corresponding meteorological information during the summer monsoon in Chengdu from May to October in 2017 and 2018 and obtained the water vapor transport path by using the Hybrid Single Particle Lagrangian Integrated Trajectory (HYSPLIT) model. The objective of this study is to investigate the temporal variation in the precipitation isotopic composition during the summer monsoon and to analyze its response to changes in moisture sources. The correlation between stable isotopes and local meteorological parameters is also discussed for different time scales. The research results in this paper will fill the gap in the precipitation stable isotope record of GNIP in Chengdu. Moreover, these results help to explain the indicative significance of biological and geological proxies to climate change in paleomonsoon climate research.

\section{Material and Methods}

\section{Study Area}

Chengdu $\left(102^{\circ} 54^{\prime}-104^{\circ} 53^{\prime} \mathrm{E}, \quad 30^{\circ} 05-31^{\circ} 26^{\prime} \mathrm{N}\right)$, one of the largest cities in western China, is located in the western Sichuan Basin, the eastern edge of the QinghaiTibet Plateau, and the hinterland of Chengdu Plain. Chengdu belongs to a sub-region of the subtropical monsoon humid climate of the East Asian monsoon climate, with obvious seasonal changes occurring in temperature and precipitation; summers are hot and rainy, and winters are mild and humid. The average annual precipitation is $927.5 \mathrm{~mm}$, and the annual average

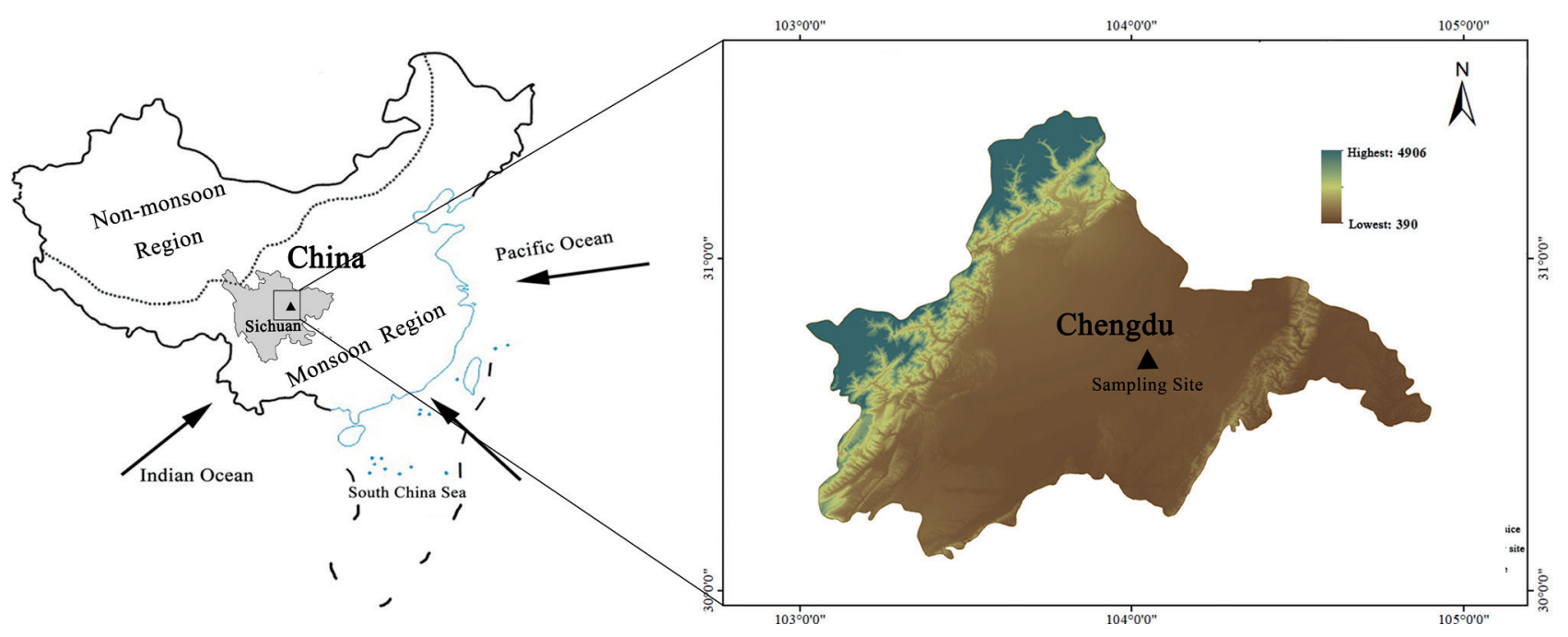

Fig. 1. Scope of the monsoon region in China and the location of the sampling site. 
temperature is $17.5^{\circ} \mathrm{C}$. More than $80 \%$ of the annual precipitation is concentrated in June to September, and the inter-annual variation in precipitation is small. The summer monsoon in East Asia first forms on the east coast of the Bay of Bengal (BoB) in May and then moves to the South China Sea (SCS). This area is alternately controlled by the summer monsoon from ocean sources and the winter monsoon from inland sources in May and June; it is completely controlled by the summer monsoon in July and August. The summer monsoon subsides gradually from late September to October. According to the characteristics of monsoon activities, the summer monsoon period is roughly divided into three sub-periods in this study: the pre-monsoon period from May to June, the prevailing period from July to August, and the declining period from September to October.

The average monthly temperature and cumulative precipitation in Chengdu during the summer monsoon period, from May to October, in 2017 and 2018 are shown in Fig. 2. The average monthly precipitation and average temperature from May to October in 1961-2003 are provided for comparison. The long-term monitoring data on temperature and precipitation were supplied by the China Meteorological Data Network (http://data.cma.cn/), and the monthly data for 2017 and 2018 were obtained from the Chengdu Public Meteorological Service Website (http://pcc.scqx.gov.cn/ sc_cd/fwcp/qhpj/). The average monthly temperature in 2017 and 2018 was not significantly different from the multi-year average. The highest and lowest values in the study period appeared in August and October, respectively. The average precipitation in Chengdu from May to October 1961-2003 was $797 \mathrm{~mm}$. The cumulative precipitation from May to October 2017 was $845.5 \mathrm{~mm}$, which is similar to the multiyear average and can represent a normal year of precipitation. The cumulative precipitation from May to October 2018 was $1259.1 \mathrm{~mm}$, which far exceeds the multi-year average. An extreme precipitation of $556 \mathrm{~mm}$ occurring in July represents an abnormal precipitation year. According to the Climate Impact Assessment Bulletin from Chongqing Meteorological Bureau (http://cq.cma.gov.cn/qxfw/qhxx/index.html), the cumulative precipitation from May to October 2017 in Chongqing, a city $200 \mathrm{~km}$ east of Chengdu, is $988.9 \mathrm{~mm}$, which is similar to the precipitation in Chengdu in the same period. The cumulative precipitation in Chongqing from May to October 2018 is $798.8 \mathrm{~mm}$, which is far below that in Chengdu in the same period. Compared with the uniform temporal distribution of monthly precipitation in Chongqing during summer monsoon, the precipitation in Chengdu is more concentrated in July and August, reflecting a more notable effect of monsoon activities.

\section{Sample Collection and Measurement}

The precipitation sampling site is located at the test site of the State Key Laboratory of Hydraulics and Mountain River Engineering, Sichuan University $\left(104.08^{\circ} \mathrm{E}, 30.63^{\circ} \mathrm{N}\right)$, at $553 \mathrm{~m}$ above sea level (asl). This site is distant from local pollution sources and tall trees or buildings, which may interfere with the rain and snow. A simple water collection device was set up according to the method recommended in the IAEA/GNIP precipitation sampling guide (http:// www-naweb.iaea.org/napc/ih/IHS_resources_gnip. html). A polyethylene (PE) bucket with a diameter of $50 \mathrm{~cm}$ and a height of $75 \mathrm{~cm}$ was first selected. Then, a smooth funnel-shaped PE film for collecting water was placed above a funnel $15 \mathrm{~cm}$ in diameter to collect the precipitation into a $500 \mathrm{~mL}$ rainwater bottle. A table tennis ball was placed in the funnel to reduce

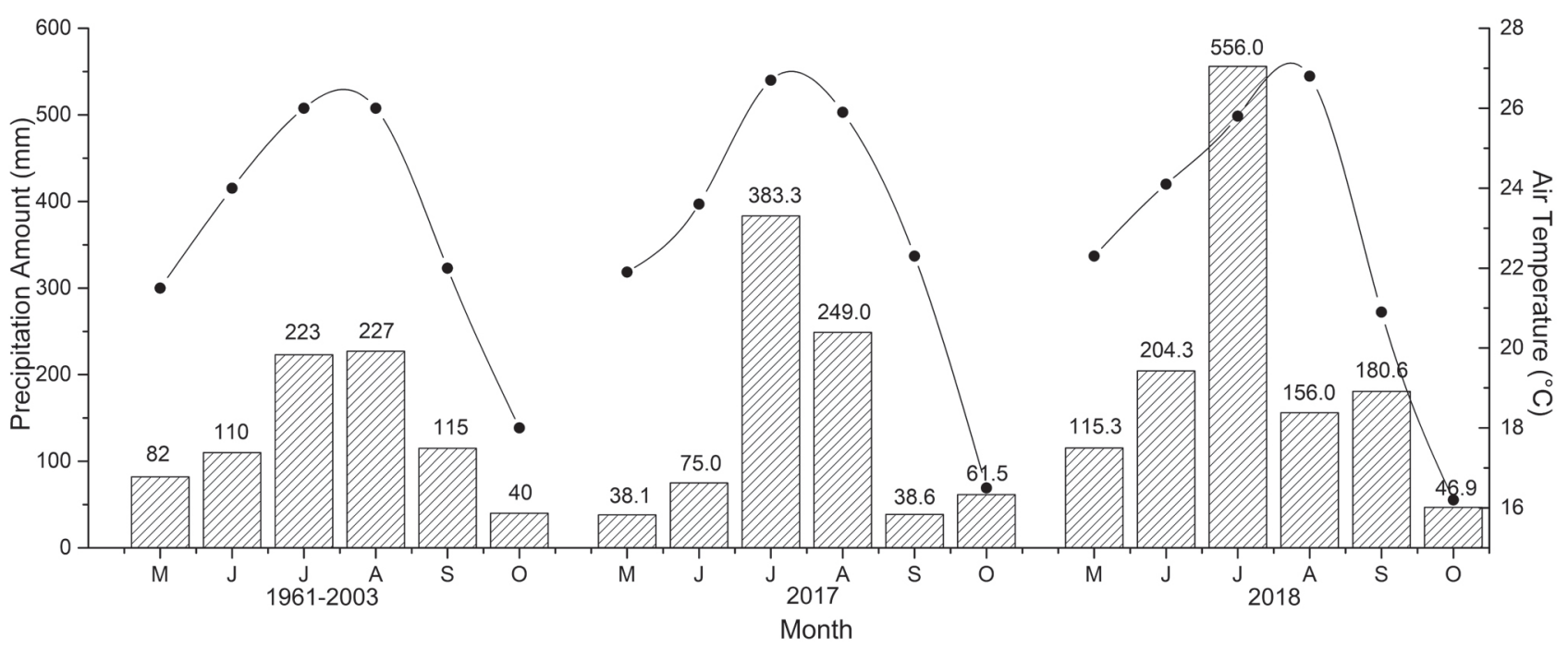

Fig. 2. Monthly data of precipitation amount and air temperature during a long-term summer monsoon monitoring period from 1961 to 2003 and in the summer monsoon periods in 2017 and 2018. 
the evaporation of collected rainwater. In order to prevent evaporation, samples were collected immediately after the precipitation ended, and the starting and ending time of precipitation, the temperature, and the precipitation amount were recorded. Meteorological information is from the Chengdu City Site data of the China Weather Network (www.weather.com.cn/). The samples were collected in a $20 \mathrm{~mL}$ PE bottle and filtered through a $0.45 \mu \mathrm{m}$ filter membrane. The sample bottle was washed with rainwater before collection. After the sample was collected, the bottle was sealed by wrapping with Parafilm sealing film and was stored in a refrigerator. If more than one precipitation event occurred in one day, each was collected and recorded as an independent event.

All collected water samples were measured by using a Triple-Liquid Water Isotope Analyzer at the College of Water Resources and Hydropower, Sichuan University. The instrument, with the model number T-LWIA-45-EP (912-0050), was developed and produced by Los Gatos Research (LGR). The measurement principle was off-axis integrated cavity output spectroscopy (OA-ICOS), which is more reliable than cavity ring down spectroscopy (CRDS). The results of isotope measurement are expressed as part per mil (\%) relative to Vienna Standard Mean Ocean Water (VSMOW). The formula is:

$$
\delta \mathrm{D}\left(\text { or } \delta^{18} \mathrm{O}\right)=\left(\mathrm{R}_{\text {sample }} / \mathrm{R}_{\text {standard }}-1\right) \times 1000 \text {. }
$$

The errors of instrumental measurement for the isotopes are $\delta \mathrm{D}<0.3 \%$, $\delta^{18} \mathrm{O}<0.08 \%$. A series of water samples (LGR1C, LGR2C, LGR3C, LGR4C, and LGR5C) prepared using OA-ICOS technology and calibrated with VSMOW-2 and SLAP-2 standard water samples (the IAEA Technical Reports Series No. 331) were used as standard reference materials for quality assurance/quality control (QA/QC). Their hydrogen and oxygen stable isotope values are shown in Table 1. According to the isotope monitoring data of atmospheric precipitation from 1986 to 1998 in the Chengdu area based on the GNIP dataset [36], the variation range of $\delta \mathrm{D}$ in the atmospheric precipitation was -85.1-6.3\%; therefore, LGR3C, LGR4C, and LGR5C were selected as reference standards in this study. In isotope analysis, the reference standards are used as verification so that the instrument can analyze the measurement conditions and reflect on whether an abnormality is presented in the analysis process according to a specified signal. A standard sample was inserted between every three samples, and each sample was collected and measured for six times. In order to eliminate the memory effect of samples, the first two measurements of a single sample were rejected. The average value of the last four measurements is considered to be close to the actual value. The test results were analyzed and calibrated by using LGR post-processing software to obtain values of $\delta \mathrm{D}$ and $\delta^{18} \mathrm{O}$ of the samples.
Table 1. Isotopic values of LGR standard samples.

\begin{tabular}{|c|c|c|}
\hline Standard Sample & $\delta \mathrm{D}_{\text {vsmow }}(\%)$ & $\delta^{18} \mathrm{O}_{\text {vsmow }}(\%)$ \\
\hline LGR1C & $-154.0 \pm 0.5$ & $-10.30 \pm 0.15$ \\
\hline LGR2C & $-123.7 \pm 0.5$ & $-8.56 \pm 0.15$ \\
\hline LGR3C & $-97.3 \pm 0.5$ & $-7.06 \pm 0.15$ \\
\hline LGR4C & $-51.6 \pm 0.5$ & $-4.17 \pm 0.15$ \\
\hline LGR5C & $-9.2 \pm 0.5$ & $-1.39 \pm 0.15$ \\
\hline
\end{tabular}

\section{HYSPLIT Back-Trajectory Model}

To identify the locations of moisture sources and to explore the relationship between isotopic composition and moisture sources of the precipitation events in Chengdu, a back-trajectory model generated by the National Oceanic and Atmospheric Administration (NOAA) was employed.

HYSPLIT is a meteorological model run by the United States National Weather Service National Centers for Environmental Prediction (NWS NCEP), using the meteorological dataset generated by the global data assimilation system (GDAS) with a $1^{\circ} \times 1^{\circ}$ grid. It has been used for the calculation and analysis of air pollutant transport and diffusion trajectories [37-40]. The $\sigma$ coordinate is used in the model, where the original format of the meteorological data is unchanged in the horizontal direction, and the data are interpolated in a vertical direction. The $\sigma$ coordinate can be calculated using the following equation:

$$
\sigma=\left(Z_{\text {top }}-Z_{\text {mst }}\right) /\left(Z_{\text {top }}-Z_{\text {gl }}\right)
$$

...where $Z_{\text {top }}$ represents the top height of the trajectory coordinate system, $Z_{\text {mst }}$ represents the height of the lower boundary, and $\mathrm{Z}_{\mathrm{gl}}$ represents the terrain height.

The model takes the integral of the time and space position vectors for the moving trajectory of air. The final position was calculated by the initial position $(\mathrm{P})$ and the first guess position $\left(\mathrm{P}_{1}\right)$ by using the following equations:

$$
\begin{gathered}
\mathrm{Q}^{\prime}(\mathrm{t}+\Delta \mathrm{t})=\mathrm{Q}(\mathrm{t})+\mathrm{V}(\mathrm{Q}, \mathrm{t}) \Delta \mathrm{t} \\
\mathrm{Q}(\mathrm{t}+\Delta \mathrm{t})=\mathrm{Q}(\mathrm{t})+0.5\left[\mathrm{~V}(\mathrm{Q}, \mathrm{t})+\mathrm{V}\left(\mathrm{Q}^{\prime}, \mathrm{t}+\Delta \mathrm{t}\right)\right] \Delta \mathrm{t},(4)
\end{gathered}
$$

...where $\mathrm{V}$ represents the kinematic velocity of the air mass, and $\Delta \mathrm{t}$ represents the time step, which was set as $6 \mathrm{~h}$ in this study.

Previous studies have shown that the heaviest amount of moisture transferred occurs $2000 \mathrm{~m}$ above the ground and that the height at $850 \mathrm{hPa}$ is thought to be approximate to the cloud base, which is about $1500 \mathrm{~m}$ asl [20, 41, 42]. Therefore, altitudes of 1500 $\mathrm{m}, 2000 \mathrm{~m}$, and $2500 \mathrm{~m}$ were chosen as the starting heights of the back-trajectory calculations in this study. The spatial data precision of the HYSPLIT model in 
this study was $1^{\circ} \times 1^{\circ}$. The start time of each precipitation was used as the initial time of the backward trajectory modeling, and the modeling duration was set to seven days (168 h).

\section{Results and Discussion}

\section{Temporal Variation of Stable Isotopes in Precipitation}

The temporal variations of $\delta \mathrm{D}$ and $\delta^{18} \mathrm{O}$ in precipitation during the summer monsoon in 2017 and 2018 are shown in Fig. 2. In 2017, 53 precipitation samples were collected. The $\delta^{18} \mathrm{O}$ in the precipitation varied from $-16.70 \%$ to $-0.68 \%$, with an arithmetic average of $-8.46 \%$ and a precipitation-weighted average of $-9.38 \%$. The $\delta \mathrm{D}$ varied from $-124.94 \%$ o to $8.65 \%$, with an arithmetic mean of $-58.00 \%$ and a precipitation weighted average of $-68.88 \%$. In 2018,78 precipitation samples were collected. The $\delta^{18} \mathrm{O}$ in precipitation varied from $-15.84 \%$ to $0.76 \%$, with an arithmetic average of $-8.56 \%$ and a precipitation-weighted average of $-10.86 \%$. The $\delta \mathrm{D}$ varied from $-119.39 \%$ o to $8.59 \%$, with an arithmetic average of $-58.51 \%$ and a precipitationweighted average of $-76.61 \%$. The variations in $\delta \mathrm{D}$ and $\delta^{18} \mathrm{O}$ reflect the changes in moisture sources and climatic conditions. The arithmetic mean and range of $\delta \mathrm{D}$ and $\delta^{18} \mathrm{O}$ in the 2017 and 2018 monsoon periods are similar, indicating that Chengdu was controlled by moisture from the same source on an annual scale, although the amount and distribution of precipitation differed significantly during the two years. The arithmetic mean treats the contribution of each precipitation data equally and is independent of the precipitation amount, whereas the weighted average emphasizes the contribution of large precipitation events. The arithmetic average values of $\delta \mathrm{D}$ and $\delta^{18} \mathrm{O}$ in both years were larger than the weighted average, indicating that precipitation amount had a significant effect on the isotopic composition during the study period, with large precipitation events showing more negative isotope values. The difference between the arithmetic and the weighted average of the isotope values in 2018 was greater than that in 2017, which is attributed to the higher total precipitation during the summer monsoon in 2018 and the higher frequency of large precipitation events.

Yapp (1982) proposed that the ratio of isotopes in the monsoon climate zone is related to strong convection and can be used to reflect the intensity of the monsoon [43]. In 2017, the isotope values were high in late May and in early June and showed a downward trend in June; they were depleted from July to October with a small fluctuation range. This variation pattern indicates that the summer monsoon began to strengthen in May and June and remained stable between July and October in that year. In 2018, high isotope values appeared in mid-May and began to decline at the end of May until the most negative value appeared in July. The isotope values in July and August maintained at very low levels and gradually increased in mid-September until the maximum value appeared in October. The variation pattern indicates that the summer monsoon strengthened in May and June, remained stable in July and August, and gradually weakened in September and October.

\section{Local Meteoric Water Line during Summer Monsoon Period}

The relationships between $\delta \mathrm{D}$ and $\delta^{18} \mathrm{O}$ in precipitation for individual events and monthly precipitation weighted values during summer monsoon period are shown in Fig. 4. In 2017 and 2018, the linear regression equations for the independent precipitation events of $\delta \mathrm{D}$ and $\delta^{18} \mathrm{O}$ during the summer monsoon are as follows:

$$
\begin{aligned}
& \text { 2017: } \delta \mathrm{D}=8.09 \delta^{18} \mathrm{O}+10.45\left(\mathrm{R}^{2}=0.98, \mathrm{n}=53\right),(5) \\
& \text { 2018: } \delta \mathrm{D}=8.10 \delta^{18} \mathrm{O}+10.82\left(\mathrm{R}^{2}=0.98, \mathrm{n}=78\right) .(6)
\end{aligned}
$$

The linear regression equations for the monthly precipitation weighted average of $\delta \mathrm{D}$ and $\delta^{18} \mathrm{O}$ precipitation are:
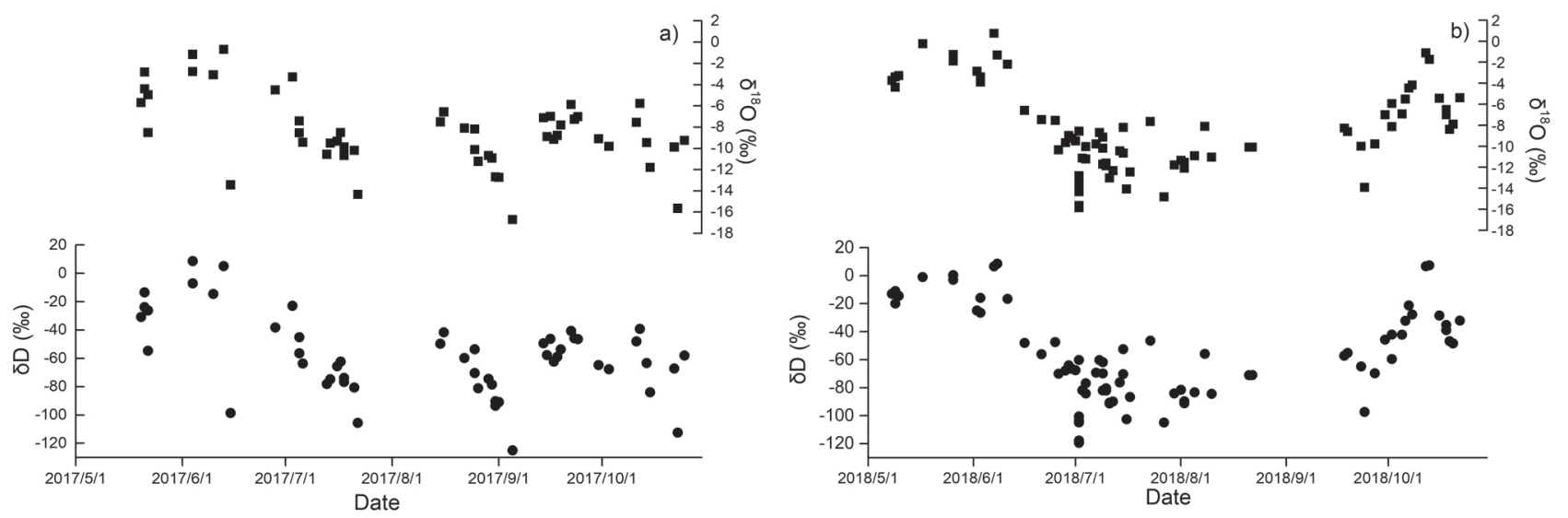

Fig. 3. Temporal variation of $\delta \mathrm{D}$ and $\delta^{18} \mathrm{O}$ in precipitation during the summer monsoon period in a) 2017 and b) 2018. 


$$
\begin{aligned}
& \text { 2017: } \delta \mathrm{D}=8.14 \delta^{18} \mathrm{O}+11.86\left(\mathrm{R}^{2}=0.99, \mathrm{n}=6\right),(7) \\
& \text { 2018: } \delta \mathrm{D}=8.34 \delta^{18} \mathrm{O}+13.68\left(\mathrm{R}^{2}=0.99, \mathrm{n}=6\right) .(8)
\end{aligned}
$$

A significant linear relationship between $\delta \mathrm{D}$ and $\delta^{18} \mathrm{O}$ was observed in both 2017 and 2018 with regression values $\left(\mathrm{R}^{2}\right)$ higher than 0.98 . Owing to the effects of condensation temperature, water vapor source, transport path, regional atmospheric circulation patterns, and meteorological conditions during the sampling period, LMWLs usually deviate from the GMWL, which considers the influence of global geographical and meteorological factors [44]. The slope of the LMWL reflects the fractionation ratio of $\delta \mathrm{D}$ and $\delta^{18} \mathrm{O}$, and the intercept reflects the extent to which $\mathrm{D}$ deviates from equilibrium [45]. In Chengdu, the slope and intercept of the LMWLs during the summer monsoon in both years were higher than those of the GMWL. Compared with the results of previous studies, the LMWL equations during the summer monsoon in Chengdu were similar to those in other cities in southern China, such as Changsha, Guangzhou, Fuzhou, and Guilin $[10,32,46,47]$. However, they were higher than those in mid-latitude monsoon regions such as Lanzhou, Fengxiang, Ningwu and Bin County [19, 28, 48], which had slopes and intercepts of usually less than 8 and 10, respectively. This indicates that in Chengdu, the precipitation moisture sources and transport path in addition to the dominant monsoon are similar to those in other cities in southern China. In the South China Monsoon Region, the air masses controlling precipitation are affected by the complex monsoon system. During the migration from ocean to land, they experience a strong fractionation effect. When precipitation occurs, however, they are less affected by non-equilibrium fractionation caused by sub-cloud secondary evaporation. The slopes and intercepts of equations (7) and (8) are higher than those of equations (5) and (6), respectively, indicating that the LMWL is related to the scale of precipitation and that small-scale precipitation tends to have lower slopes and intercepts. This occurs because during a small precipitation event, it is difficult for the atmosphere to reach saturation; therefore, the atmosphere is susceptible to sub-cloud secondary evaporation, making the fractionation ratio of $\mathrm{D}$ and ${ }^{18} \mathrm{O}$ lower than 8:1. Although significant differences were noted in the amount and distribution of precipitation during the summer monsoon in 2017 and 2018, the LMWLs of the two years were similar, indicating that the slope and intercept of LMWL have little relation to the change in climate conditions but are related mainly to the moisture sources and evaporation conditions.

In both years, some isotopic scatters in the pre-monsoon and declining periods fell above the LMWLs and deviated from the regression line to a large extent, representing precipitation occurring under atmospheric conditions with low temperature and low water vapor content. In the pre-monsoon period, many scatters deviated significantly from the LMWLs and fell below them, reflecting the occurrence of non-equilibrium fractionation during the landing processes of raindrops owing to sub-cloud secondary evaporation. This is consistent with the climate characteristics of less precipitation and higher temperature in May and June. During the prevailing period in both years, the isotope scatters were distributed evenly around the LMWLs, indicating that the moisture during this period was mainly from the ocean, the air humidity was relatively large, and that the isotopes in the raindrops were less affected by the non-equilibrium fractionation.
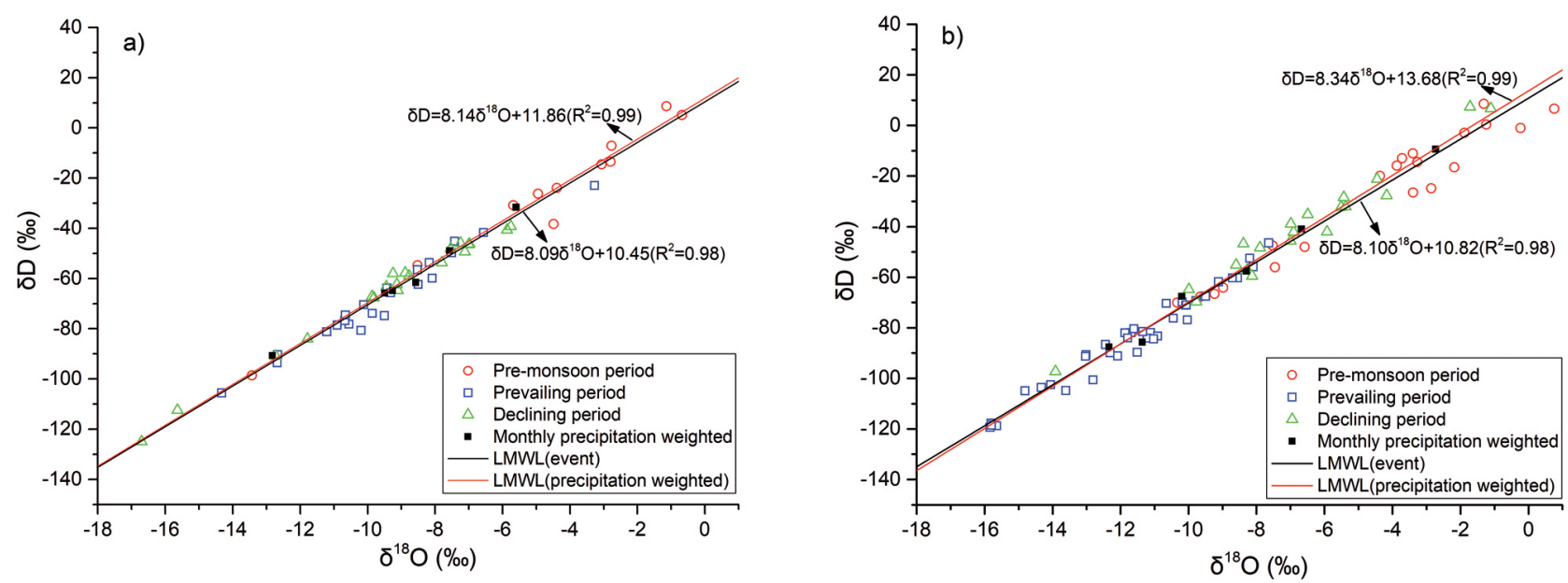

Fig. 4. Linear regression between $\delta^{18} \mathrm{O}$ and $\delta \mathrm{D}$ in precipitation during the summer monsoon period in a) 2017 and b) 2018; the red circles, blue squares, and green triangles represent precipitation events during the pre-monsoon period, prevailing period, and declining period, respectively, and the black squares represent the monthly precipitation weighted values; the black lines represent LMWLs for individual samples, and the red lines represent LMWLs for monthly precipitation-weighted data. 


\section{Isotopic Responses to the Moisture Sources}

Under unsaturated conditions, the equilibrium fractionation of $\mathrm{D}$ and ${ }^{18} \mathrm{O}$ is degraded during evaporation and condensation. Differences occur in the relationship between $\delta \mathrm{D}$ and $\delta^{18} \mathrm{O}$ among different regions and meteorological conditions. Dansgaard (1964) first defined d-excess to describe this difference such that $\mathrm{d}$-excess $=\delta \mathrm{D}-8 \delta^{18} \mathrm{O}$, and the average d-excess value of global precipitation is equal to 10 [17]. Because D-excess is sensitive to physical processes that produce intense kinetic fractionation, it has been used in many studies to reflect the degree of nonequilibrium fractionation of isotopes during evaporation and condensation [3, 20]. During the processes of atmospheric circulation, d-excess depends mainly on the meteorological conditions of the moisture source, which is negatively correlated with the relative humidity of the evaporation surface and positively correlated with the temperature [44]. It is also subject to recycled moisture, sub-cloud material exchanges, and secondary evaporation $[19,20,49]$. In the mid-low-latitude monsoon regions of China, the d-excess in precipitation is generally higher than 10 during the winter monsoon and is lower or slightly higher than 10 during the summer monsoon, by which the climatic conditions of the moisture source can be judged accordingly. The $\delta^{18} \mathrm{O}$ and d-excess changes in precipitation event during the 2017 and 2018 summer monsoons are shown in Fig. 5.

The average d-excess values for precipitation during the summer monsoon periods of 2017 and 2018 were 9.71 and 9.97 , respectively, indicating that the region was dominated mainly by oceanic moisture. These values are similar to the monitored data of Hong Kong, Guangzhou, and Changsha, which are located in the subtropical monsoon region of China [32, 47]. This indicates that Chengdu and these cities may have a similar water vapor source. The d-excess and $\delta^{18} \mathrm{O}$ showed significant temporal fluctuations, indicating that the source of water vapor affecting precipitation in Chengdu during the summer monsoon is complicated. From May to midJune 2017, the d value of most precipitation events was higher than the global average, and the precipitation $\delta^{18} \mathrm{O}$ was also relatively enriched - likely because the water vapor of precipitation originated mainly from the inland areas. The highest value of d-excess was 17.81, which occurred on June 4. From the beginning of June, d-excess gradually declined until a minimum value of -2.33 occurred on June 28. Except for a minimum value of -13.43 on June 15 , the $\delta^{18} \mathrm{O}$ in precipitation events was higher during this period. Therefore, the decrease in d-excess was likely affected by local meteorological conditions rather than the change in water vapor source. The precipitation amount in Chengdu in June 2017 was significantly lower than the multi-year average. In addition, the warm and dry atmosphere would have caused non-equilibrium fractionation of isotopes in the sub-cloud processes, which may explain the decrease in $\mathrm{d}$ value. The depleted $\delta^{18} \mathrm{O}$ on June 15 may by the result of isotope fractionation caused by continuous precipitation. In early July, both the $\delta^{18} \mathrm{O}$ and d-excess continued to decline, indicating enhancement in the summer monsoon and an increase in the proportion of moisture from the distant ocean. Except for a maximum value of 14.29 on July 5, the value of d-excess in precipitation was lower than the global average from early July to mid-August and was accompanied by depleted $\delta^{18} \mathrm{O}$. This indicates that the precipitation moisture formed in evaporation conditions with high relative humidity, which may have been derived from low-latitude oceans. The high d value on July 5 with a lower $\delta^{18} \mathrm{O}$ may be related to the contribution of recycled moisture. D-excess values far below the global average occurred in events on July 14 and 21 and August 22, when the temperature was high and the precipitation amount was low. The occurrence of low $d$ values may be attributed to the non-equilibrium fractionation caused by strong sub-cloud secondary evaporation. From late August to mid-September, the d-excess value of
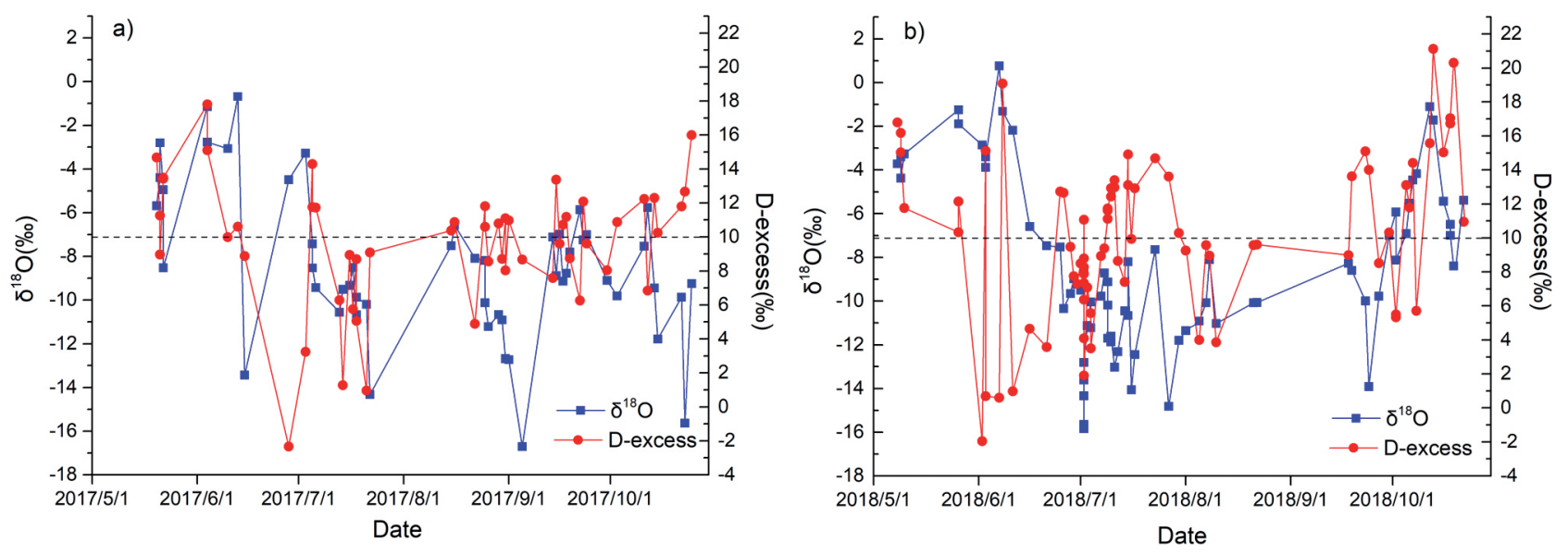

Fig. 5. Temporal variations in $\delta^{18} \mathrm{O}$ and d-excess in precipitation during the summer monsoon period in a) 2017 and b) 2018 ; the horizontal dashed line represents the global average d value of $10 \%$. 
precipitation fluctuated around the global average, and the amount of fluctuation increased gradually. This can be explained by the increasing contribution of moisture from the arid inland to Chengdu's precipitation. In mid-September, the d-excess in precipitation showed a gradual increasing trend. However, the $\delta^{18} \mathrm{O}$ still showed a negative value, which cannot be explained simply by changes in the moisture source; the effects of local meteorological conditions are also considered.

The variation patterns of d-excess and $\delta^{18} \mathrm{O}$ in the precipitation events during the summer monsoon in 2018 are different from those in 2017. The concentration of $\delta^{18} \mathrm{O}$ in precipitation in May was higher and was accompanied by a d-excess value greater than the global average, indicating an inland moisture source. The continuous decrease in $\delta^{18} \mathrm{O}$ in June indicates the onset of the summer monsoon and an increase in the contribution of ocean-source moisture. The d-excess showed large fluctuation, with a minimum value of -1.95 on June 2 and a maximum value of 19.09 on June 8 , which may be attributed to the fierce competition between the ocean and inland moisture when the air masses from different sources alternately controlled this area. Another possible cause is the effect of subcloud secondary evaporation under such meteorological conditions of dryness and high temperature. In July and August 2018, the $\delta^{18} \mathrm{O}$ remained at a low value, reflecting the "rainout effect" experienced by distant oceansource moisture during transport. Many extremely low $\delta^{18} \mathrm{O}$ records appeared during these two months, which is possibly related to frequent typhoons and cyclonic activities. The $\delta^{18} \mathrm{O}$ in precipitation caused by these extreme weather events is usually lower than that of normal precipitation [50]. Although the typhoons and tropical cyclones formed in the SCS and the Western Pacific did not pass through Chengdu directly, they caused severe convective weather and torrential rain. In addition, they brought a large amount of moisture from the distant ocean, which made the moisture supply in Chengdu more complicated and led to the observed negative value of $\delta^{18} \mathrm{O}$. The $\delta^{18} \mathrm{O}$ did not exhibit a sustained low value, which is consistent with the short duration of a typhoon's impact. The d-excess fluctuated at around 10 and showed a large range of volatility, reflecting frequent changes in the dominant monsoon during this period. In mid-September, moisture evaporated from the underlying surface may have contributed to the precipitation with a negative $\delta^{18} \mathrm{O}$ and a higher $\mathrm{d}$ value. The values of $\delta^{18} \mathrm{O}$ and d-excess in the precipitation began to increase rapidly in late September, reflecting a weakening of the summer monsoon and a reduction in the proportion of ocean-source moisture in the precipitation. The contribution of inland water vapor with high isotope content resulted in the increase of $\delta^{18} \mathrm{O}$ in the precipitation.

The responses of $\delta^{18} \mathrm{O}$ and d-excess to the water vapor sources can be verified and further explained by the HYSPLIT air mass backward trajectory model. The modeling results for the eight selected periods during the 2017 summer monsoon are shown in Fig. 6. When the summer monsoon began to form in mid-May (Fig. 6a), the moisture contributing to the precipitation with low $\delta^{18} \mathrm{O}$ and high d-excess showed an inland source. At $2000 \mathrm{~m}$ and $1500 \mathrm{~m}$ levels, the moisture was carried by the inland air masses from the westerly belt, and at the height of $2500 \mathrm{~m}$, the moisture originated from surface evaporation nearby. The inland air mass had a low relative humidity and strong evaporation. The isotopes experienced a weak rainout effect during the transport of the air masses and became continuously enriched owing to absorption of the evaporated moisture, which resulted in high $\delta^{18} \mathrm{O}$ and d-excess values. The moisture that caused the higher $\delta^{18} \mathrm{O}$ value in the June precipitation still originated from remote inland areas (Fig. 6b, c). During this period, Chengdu was controlled by dry air masses from western or northern inland areas, and the heavy isotopes were more enriched. At the same time, the enrichment of $\delta^{18} \mathrm{O}$ and the decrease of d-excess were consistent with the effects of sub-cloud secondary evaporation. The high temperature and low precipitation during this period caused the atmosphere to become unsaturated, and raindrops experienced strong non-equilibrium fractionation during the landing process. On June 4 (Fig. 6b), except for the air mass from the westerly zone at $2000 \mathrm{~m}$, the air masses at heights of $1500 \mathrm{~m}$ and $2500 \mathrm{~m}$ originated from adjacent areas; therefore, the maximum value of d-excess in precipitation may be attributed to the contribution of recycled moisture caused by surface evaporation. In July and August, Chengdu was controlled by tropical air masses from the BoB and the SCS (Fig. 6d-f). Marine air mass has high relative humidity and weak evaporation. During the process of inward transportation, the heavy isotope was gradually depleted by the strong rainout effect as the precipitation continued to form. Owing to the large relative humidity of the ocean evaporation surface, the d-excess value of the water vapor was low. On July 5, evaporation from the land surface at a height of $1500 \mathrm{~m}$ may have contributed to the precipitation with a high d-value (Fig. 6d). At the end of August, the air masses causing precipitation originated from the ocean at $2000 \mathrm{~m}$ and $3000 \mathrm{~m}$, and from the northern inland at $1500 \mathrm{~m}$ (Fig. 6g), indicating that the summer monsoon began to subside and the winter monsoon became active during this period. The fluctuation in the $\mathrm{d}$ value can be explained by a change in the ratio of inland and ocean moisture. At the end of the summer monsoon, the air masses of the precipitation originated from the far-source westerly zone at three different levels, which carried the arid inland moisture (Fig. 6h); therefore, the observed low value of $\delta^{18} \mathrm{O}$ was not the result of oceansource moisture. Pang et al. (2006) reported that the low value of $\delta^{18} \mathrm{O}$ at the end of the monsoon period is caused by the evaporation of water vapor during the prevailing monsoon period [51]. In Chengdu, the precipitation during the prevailing monsoon period in 2017 was large. Owing to this injection of precipitation, the underlying surface was relatively moist, which resulted in strong 

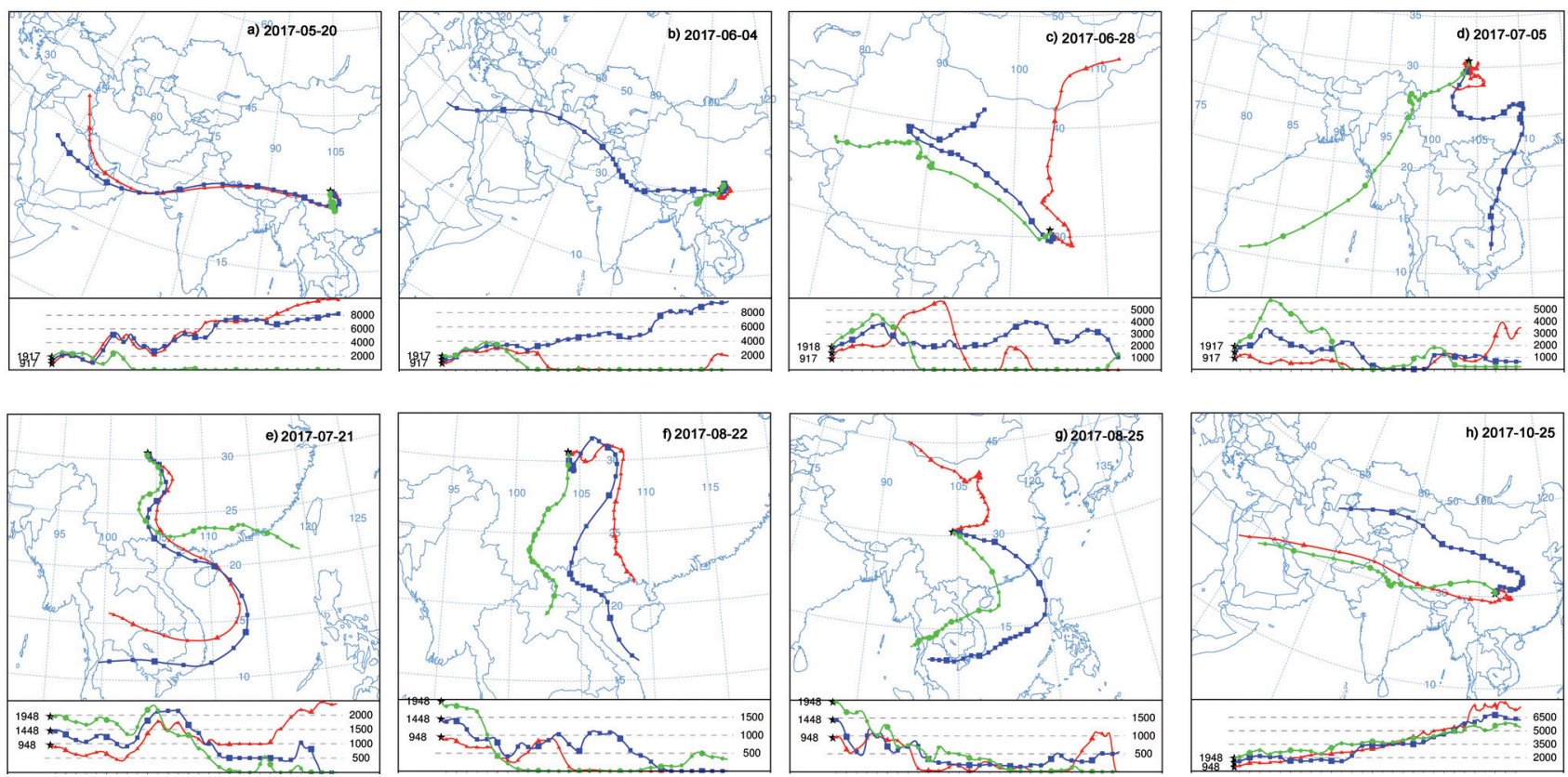

Fig. 6. Results of modeled back trajectories for air masses for eight selected precipitation events in 2017; the green, blue, and red lines represent $2500 \mathrm{~m}, 2000 \mathrm{~m}$, and $1500 \mathrm{~m}$ height levels of air-mass trajectories, respectively.
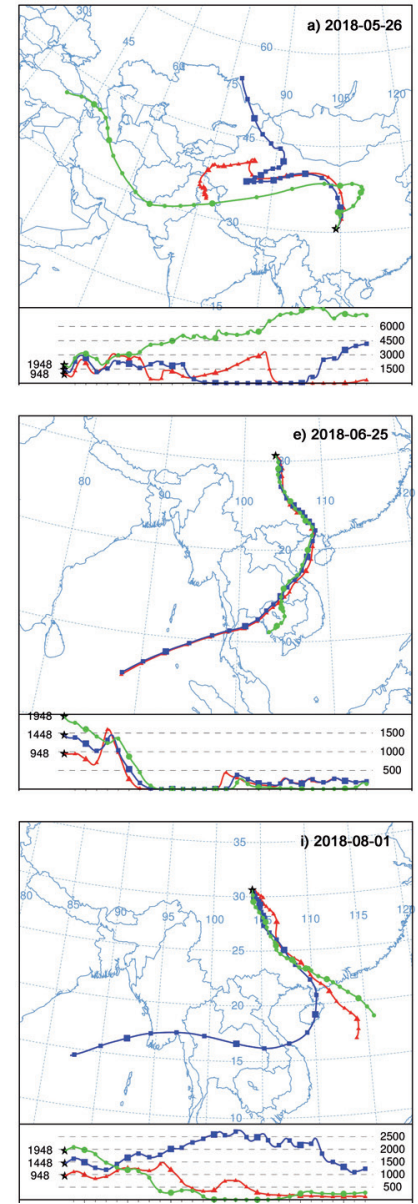
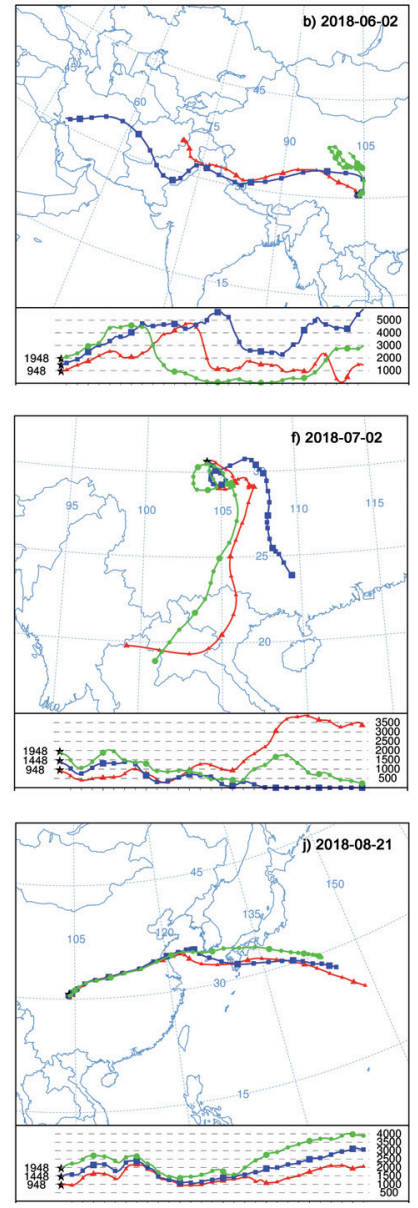
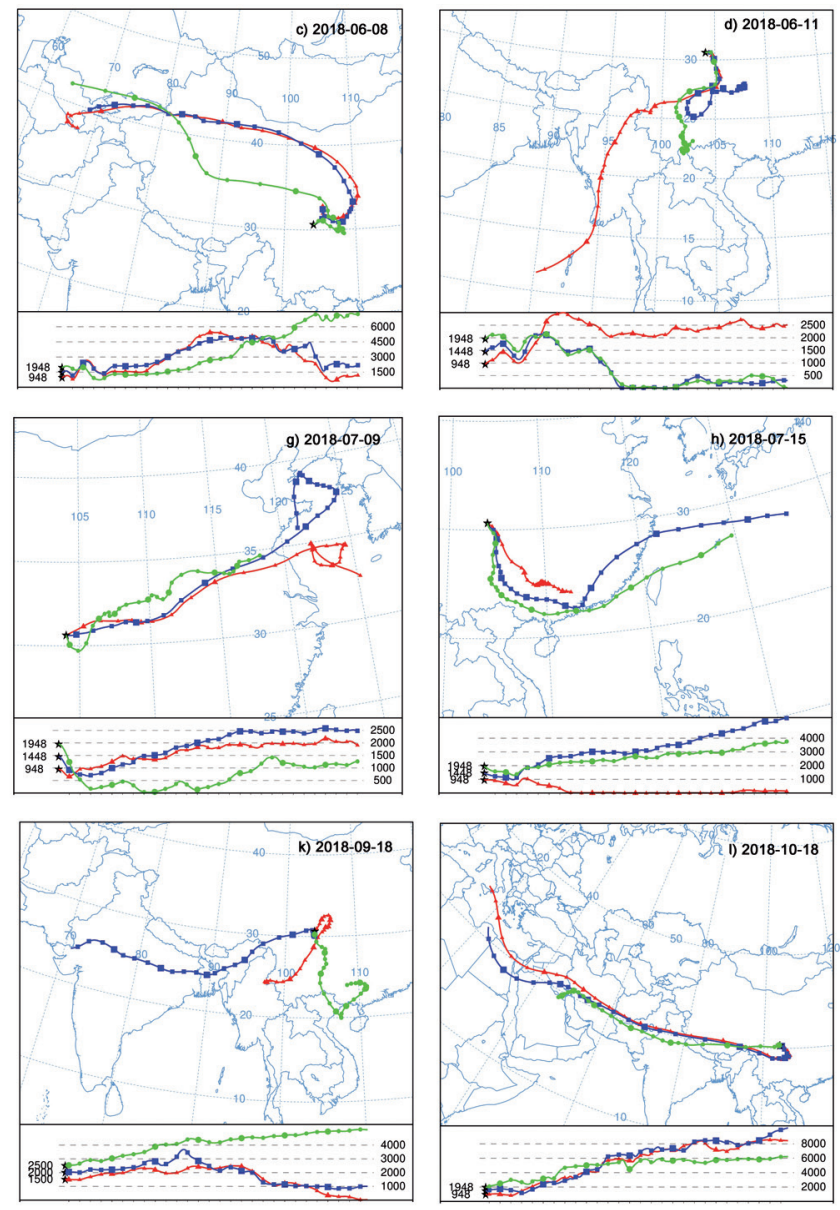

Fig. 7. Results of modeled back trajectories for air masses in 12 selected precipitation events in 2018; the green, blue and red lines represent $2500 \mathrm{~m}, 2000 \mathrm{~m}$, and $1500 \mathrm{~m}$ height levels of air-mass trajectories, respectively. 
surface evaporation at the end of the monsoon. The moisture enriched in light isotopes evaporated into the atmosphere and re-formed as precipitation, which may have caused the negative $\delta^{18} \mathrm{O}$ value.

The results of the modeled air mass trajectories for the 12 selected time periods in 2018 are shown in Fig. 7. In May, air masses that caused precipitation with less negative $\delta^{18} \mathrm{O}$ and higher $\mathrm{d}$ values were derived from the mid-high-latitude inland areas on all three levels (Fig. 7a). The precipitation with higher $\delta^{18} \mathrm{O}$ in early June was derived mainly from inland water vapor in the westerly zone (Fig. 7b, c). Although the precipitation on June 2 and June 8 contained disparate values of $\mathrm{d}$, the trajectory analysis revealed similar sources of air masses on three levels - all from inland. Therefore, the assumption that moisture from different sources caused the changes in d-excess is overturned. The several extremely low d-excess values in early June may be attributed to sub-cloud secondary evaporation under conditions of high temperature, low precipitation, and low relative humidity. In mid-June, the air masses originated from the $\mathrm{BoB}$ at a height of $1500 \mathrm{~m}$ and from the inland surface at $2000 \mathrm{~m}$ and $2500 \mathrm{~m}$ (Fig. 7d). This shows the period of transition from continental monsoon to marine monsoon, which is consistent with the decline of $\delta^{18} \mathrm{O}$ in precipitation. In late June, at the three levels, the air masses were all derived from the BoB (Fig. 7e). This indicates that the area was controlled by the marine monsoon, which is consistent with the negative $\delta^{18} \mathrm{O}$ and low $\mathrm{d}$ values in precipitation. In July and August, the results of the backward trajectory model showed that the sources of precipitation air masses included the SCS, the $\mathrm{BoB}$ and the Western Pacific (Fig. 7f-j), showing the combined effects of the southwest and southeast monsoons. The combination and variation of air masses from different sources caused complex moisture composition during this period. Owing to the different initial meteorological conditions and transport distances, the moisture carried by air masses from different sources had different isotopic compositions, resulting in fluctuations in $\delta^{18} \mathrm{O}$ and d-excess in the precipitation. In mid-September, the precipitation air masses at 2000 $\mathrm{m}$ and $2500 \mathrm{~m}$ levels still originated from the ocean, whereas those at $1500 \mathrm{~m}$ level were from the inland surface (Fig. 7k); this indicates weakening of the summer monsoon. The higher d values may have been subject to the moisture contribution from inland evaporation. In October, moisture contributing to precipitation with an increasing $\delta^{18} \mathrm{O}$ and high d-value was derived from the westerly zone for all three levels, reflecting the isotope characteristics of dry inland moisture.

Significant differences were noted between the atmospheric circulation patterns during the summer monsoon in 2017 and 2018. In 2017, the summer monsoon began to control Chengdu in early July, and the moisture was carried mainly by tropical warm-moist air masses from the SCS and the $\mathrm{BoB}$ during the active monsoon period. In late August, the summer monsoon gradually subsided. However, the summer monsoon of 2018 controlled this region in late June, and the moisture from the SCS, the BoB, and the Western Pacific alternately controlled this region during the active monsoon period. In mid-September, the summer monsoon began to weaken. The summer monsoon in 2018 lasted for a long time, with heavy precipitation, causing more negative $\delta^{18} \mathrm{O}$ in precipitation. In addition, the more complicated water vapor source caused the fluctuation of d-excess to be greater. Generally, the values of $\delta^{18} \mathrm{O}$ and d-excess in precipitation during the summer monsoon are consistent with the source information of the air masses provided by the HYSPLIT model. The precipitation contributed by the moisture from the ocean warm and humid air masses has more negative $\delta^{18} \mathrm{O}$ and lower d-excess values, and that contributed by the moisture carried from inland dry air masses has less negative or even positive $\delta^{18} \mathrm{O}$ and higher $\mathrm{d}$-excess values, indicating a strong correlation between the isotope composition and the moisture source of the precipitation events. The onset and decline of the summer monsoon and the intensity changes in different periods is well reflected in the isotope composition. However, for some precipitation events, especially those occurring during the transition period between the continental monsoon and the ocean monsoon, the values of $\mathrm{d}$ and $\delta^{18} \mathrm{O}$ were also susceptible to other factors, such as local temperature, precipitation amount, and evaporation conditions, so that they reflect more factors comprehensively. Although the trajectory model can provide source information of the air masses, it cannot explain the isotope characteristics separately, which needs to consider local meteorological conditions.

\section{Effects of Local Meteorological Parameters on Isotopic Compositions}

The record of paleoclimate by biological and geological proxies is closely related to $\delta^{18} \mathrm{O}$ and $\delta \mathrm{D}$ in atmospheric precipitation. Understanding the relationship between isotopic composition in precipitation and local meteorological factors plays a key role in revealing the paleoclimatic information contained in the proxies. To understand the response of precipitation isotopes to climatic processes, linear regression was used to evaluate the relationship between meteorological parameters and isotopic composition. The correlation coefficient and significance test were performed by Person's Method and two-tailed tests, respectively.

\section{Correlation between $\delta^{18} \mathrm{O}$ and Precipitation Amount}

The precipitation effect is a negative correlation between precipitation and isotope values [17]. Moisture from a certain source experiences isotope fractionation during transportation owing to the continuous precipitation, resulting in the depletion of heavy isotopes in the residual vapor. In the southern monsoon region of China, the influence of the precipitation amount on isotopes is often significant $[10,52,53]$. 
Linear regression of the $\delta^{18} \mathrm{O}$-precipitation amount (P) relationship during the 2017 and 2018 summer monsoon periods and sub-periods was performed by using the least squares method. The results are shown in Fig. 8. During the entire summer monsoon in 2017 and $2018, \delta^{18} \mathrm{O}$ and precipitation showed a negative correlation, which was significant at the 0.05 and 0.01 confidence levels (Fig. $8 \mathrm{~d}, \mathrm{~h}$ ). This indicates that the isotopes in the precipitation were affected by the precipitation effect and is consistent with the results of the rainy season at other sites in the southern monsoon region of China. In 2017, the precipitation of $\delta^{18} \mathrm{O}$ in the pre-monsoon and declining periods showed negative correlations with precipitation, which reflected a precipitation effect. However, the slopes of the $\delta^{18} \mathrm{O}-\mathrm{P}$ regression lines in the two sub-periods varied greatly. In the prevailing period, $\delta^{18} \mathrm{O}$ showed a positive correlation with precipitation, which is inconsistent with the influence of precipitation on the isotope fractionation mechanism, indicating that the isotope changes during this period were affected by other factors. In 2018, the precipitation isotopes of the three sub-periods showed precipitation effects, although the slopes of the $\delta^{18} \mathrm{O}-\mathrm{P}$ regression line were significantly different. This reflects that the precipitation amount affected isotopes differently in the different periods. The correlation coefficient (r) reflects the degree of linear correlation between the variables. For the entire summer monsoon in 2017 and 2018, the $r$ values were -0.23 and -0.36 , respectively. In each sub-period of 2017 and 2018, the absolute value of $\mathrm{r}$ of the $\delta^{18} \mathrm{O}-\mathrm{P}$ regression line was smallest ( 0.27 for 2017 and 0.12 for 2018, respectively) in the prevailing monsoon period and was accompanied by the gentlest slope ( 0.05 for 2017 and 0.01 for 2018, respectively). The regression lines of this sub-period in both years did not pass the significant test of the 0.05 confidence level (Fig. 8b, f), which indicates that precipitation was not the major factor affecting isotope variation during this sub-period. This may be because the isotopic composition of the moisture contributing to precipitation during this period is subject to change. The precipitation air masses and the transport path of moisture vary greatly because they are influenced by multiple monsoons. The meteorological conditions of the source areas create differences in the initial isotopic composition of the moisture, and differences in the transport path causes fractionation of different degrees in the isotopes in the moisture before it reaches Chengdu. The maximum of absolute values of slope $(0.55)$ and $\mathrm{r}(0.76)$ appeared in the pre-monsoon period of 2017, which is likely attributed to scarce precipitation and high temperature. The small precipitation event had a higher $\delta^{18} \mathrm{O}$ value owing to strong sub-cloud secondary evaporation, partially accounting for the precipitation effects. These results are consistent with the conclusions described above.

\section{Correlation between $\delta^{18} \mathrm{O}$ and Air Temperature}

Correspondence was also noted between the ground and condensation temperatures of the precipitation air mass; the latter is related directly to the isotope fractionation coefficient. According to the Rayleigh Fractionation Model, a lower condensation temperature relates to a larger isotope fractionation coefficient $\alpha$ and a lower $\delta$ value. Dansgaard (1964) defined the positive correlation between precipitation stable isotopes and temperature as the temperature effect [17]. The values of $\delta^{18} \mathrm{O}$ in precipitation events and air temperature are shown in Table 2. Linear regressions of $\delta^{18} \mathrm{O}$-temperature $(\mathrm{T})$ during the summer monsoon periods in 2017 and 2018 and in the sub-periods were performed by using the least squares method. The results are shown in Fig. 8. In 2017, weak positive correlation existed between precipitation $\delta^{18} \mathrm{O}$ and temperature during the entire summer monsoon and
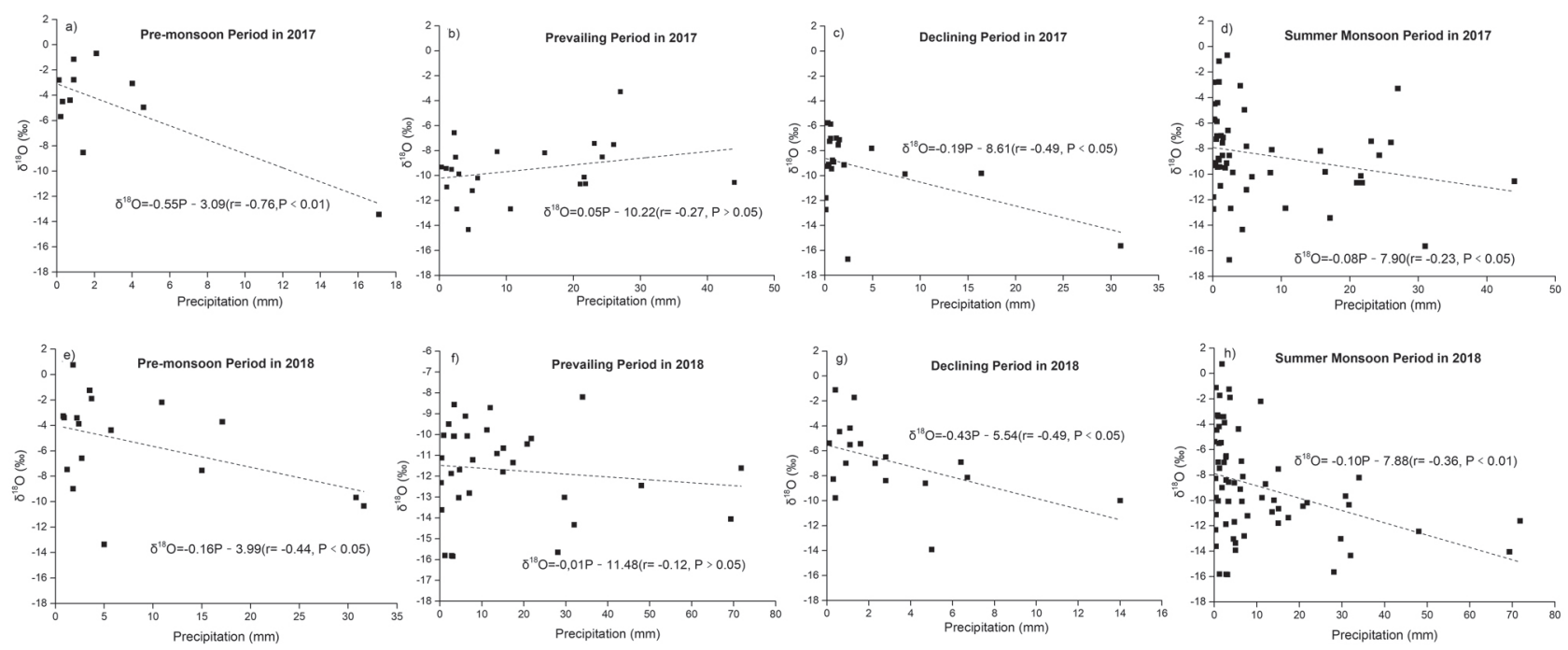

Fig. 8. Linear regressions between precipitation amount and $\delta^{18} \mathrm{O}$ in precipitation; panels a-d) represent $\delta^{18} \mathrm{O}-$ precipitation $(\mathrm{P})$ correlations in different periods in 2017; e-h) represent $\delta^{18} \mathrm{O}-\mathrm{P}$ correlations in different periods in 2018 
Table 2. Values of $\delta^{18} \mathrm{O}$ and air temperature for precipitation events.

\begin{tabular}{|c|c|c|c|c|c|c|c|c|}
\hline Date & $\delta^{18} \mathrm{O}(\% 0)$ & $\mathrm{T}\left({ }^{\circ} \mathrm{C}\right)$ & Date & $\delta^{18} \mathrm{O}(\% 0)$ & $\mathrm{T}\left({ }^{\circ} \mathrm{C}\right)$ & Date & $\delta^{18} \mathrm{O}(\% 0)$ & $\mathrm{T}\left({ }^{\circ} \mathrm{C}\right)$ \\
\hline 20170520 & -5.68 & 21.2 & 20170924 & -7.00 & 24.6 & 20180708 & -8.71 & 24.7 \\
\hline 20170521 & -4.39 & 22.3 & 20170903 & -9.10 & 22.9 & 20180709 & -9.12 & 21.7 \\
\hline 20170521 & -2.80 & 24.4 & 20171003 & -9.82 & 19.0 & 20180709 & -10.19 & 22.3 \\
\hline 20170522 & -4.95 & 22.1 & 20171011 & -7.54 & 17.1 & 20180709 & -11.69 & 22.5 \\
\hline 20170522 & -8.52 & 22.1 & 20171012 & -5.76 & 18.7 & 20180710 & -11.87 & 22.1 \\
\hline 20170604 & -1.14 & 20.2 & 20171014 & -9.45 & 20.0 & 20180710 & -11.61 & 25.0 \\
\hline 20170604 & -2.77 & 21.6 & 20171015 & -11.78 & 18.7 & 20180711 & -13.01 & 21.0 \\
\hline 20170601 & -3.06 & 23.8 & 20171022 & -9.87 & 14.8 & 20180711 & -13.03 & 21.5 \\
\hline 20170613 & -0.68 & 22.7 & 20171023 & -15.64 & 19.5 & 20180712 & -12.31 & 22.5 \\
\hline 20170615 & -13.43 & 19.4 & 20171025 & -9.25 & 15.0 & 20180714 & -10.45 & 27.2 \\
\hline 20170628 & -4.49 & 25.7 & 20180508 & -3.72 & 18.0 & 20180715 & -10.66 & 25.0 \\
\hline 20170703 & -3.27 & 27.1 & 20180509 & -3.40 & 16.5 & 20180715 & -8.20 & 24.0 \\
\hline 20170705 & -7.42 & 24.6 & 20180509 & -4.37 & 15.5 & 20180716 & -14.06 & 25.5 \\
\hline 20170705 & -8.53 & 25.3 & 20180510 & -3.27 & 16.0 & 20180717 & -12.45 & 25.5 \\
\hline 20170706 & -9.43 & 23.2 & 20180517 & -0.23 & 22.0 & 20180723 & -7.64 & 24.8 \\
\hline 20170713 & -10.55 & 26.6 & 20180526 & -1.24 & 22.5 & 20180727 & -14.81 & 27.6 \\
\hline 20170714 & -9.50 & 27.2 & 20180526 & -1.89 & 21.0 & 20180730 & -11.79 & 25.0 \\
\hline 20170716 & -9.32 & 25.1 & 20180602 & -2.86 & 20.0 & 20180801 & -11.35 & 26.8 \\
\hline 20170717 & -8.51 & 26.8 & 20180603 & -3.88 & 21.5 & 20180805 & -10.91 & 32.0 \\
\hline 20170718 & -10.68 & 26.6 & 20180603 & -3.40 & 21.0 & 20180807 & -10.08 & 26.0 \\
\hline 20170718 & -9.86 & 26.7 & 20180607 & 0.76 & 27.0 & 20180808 & -8.10 & 27.5 \\
\hline 20170721 & -10.20 & 30.1 & 20180608 & -1.31 & 25.6 & 20180821 & -10.07 & 27.0 \\
\hline 20170722 & -14.33 & 28.7 & 20180611 & -2.18 & 23.5 & 20180918 & -8.27 & 23.5 \\
\hline 20170815 & -7.51 & 27.2 & 20180616 & -6.58 & 20.5 & 20180919 & -8.60 & 23.0 \\
\hline 20170816 & -6.57 & 25.3 & 20180621 & -7.46 & 23.5 & 20180923 & -9.99 & 22.5 \\
\hline 20170822 & -8.08 & 27.8 & 20180625 & -7.53 & 23.8 & 20180924 & -13.91 & 20.0 \\
\hline 20170825 & -8.18 & 25.1 & 20180626 & -10.34 & 26.9 & 20180927 & -9.77 & 20.5 \\
\hline 20170825 & -10.12 & 24.2 & 20180628 & -9.66 & 26.0 & 20180930 & -7.00 & 21.0 \\
\hline 20170826 & -11.21 & 24.1 & 20180629 & -8.98 & 27.6 & 20181002 & -5.93 & 19.1 \\
\hline 20170829 & -10.66 & 22.3 & 20180630 & -9.24 & 28.5 & 20181002 & -8.13 & 18.0 \\
\hline 20170830 & -10.91 & 22.0 & 20180701 & -9.50 & 25.0 & 20181005 & -6.91 & 19.0 \\
\hline 20170831 & -12.67 & 21.8 & 20180702 & -8.56 & 26.1 & 20181006 & -5.51 & 18.5 \\
\hline 20170831 & -12.69 & 23.0 & 20180702 & -14.33 & 24.0 & 20181007 & -4.46 & 17.5 \\
\hline 20170901 & -12.73 & 22.3 & 20180702 & -15.65 & 22.1 & 20181008 & -4.17 & 17.0 \\
\hline 20170905 & -16.70 & 24.0 & 20180702 & -15.84 & 22.1 & 20181012 & -1.11 & 15.5 \\
\hline 20170914 & -7.12 & 23.1 & 20180702 & -15.81 & 22.4 & 20181013 & -1.72 & 14.5 \\
\hline 20170915 & -8.89 & 23.4 & 20180702 & -15.80 & 22.5 & 20181016 & -5.44 & 19.5 \\
\hline 20170916 & -6.98 & 22.8 & 20180702 & -13.61 & 22.3 & 20181018 & -6.49 & 15.0 \\
\hline 20170917 & -9.13 & 22.2 & 20180702 & -12.81 & 22.4 & 20181018 & -6.99 & 15.5 \\
\hline
\end{tabular}


Table 2. Continued.

\begin{tabular}{|l|c|c|c|c|c|c|c|c|}
\hline 20170918 & -8.77 & 24.3 & 20180703 & -11.12 & 23.0 & 20181019 & -8.39 & 14.9 \\
\hline 20170919 & -7.80 & 23.7 & 20180704 & -11.22 & 23.1 & 20181020 & -7.90 & 15.0 \\
\hline 20170922 & -5.87 & 25.1 & 20180704 & -10.04 & 23.5 & 20181022 & -5.38 & 16.0 \\
\hline 20170923 & -7.24 & 22.2 & 20180707 & -9.78 & 24.0 & & & \\
\hline
\end{tabular}
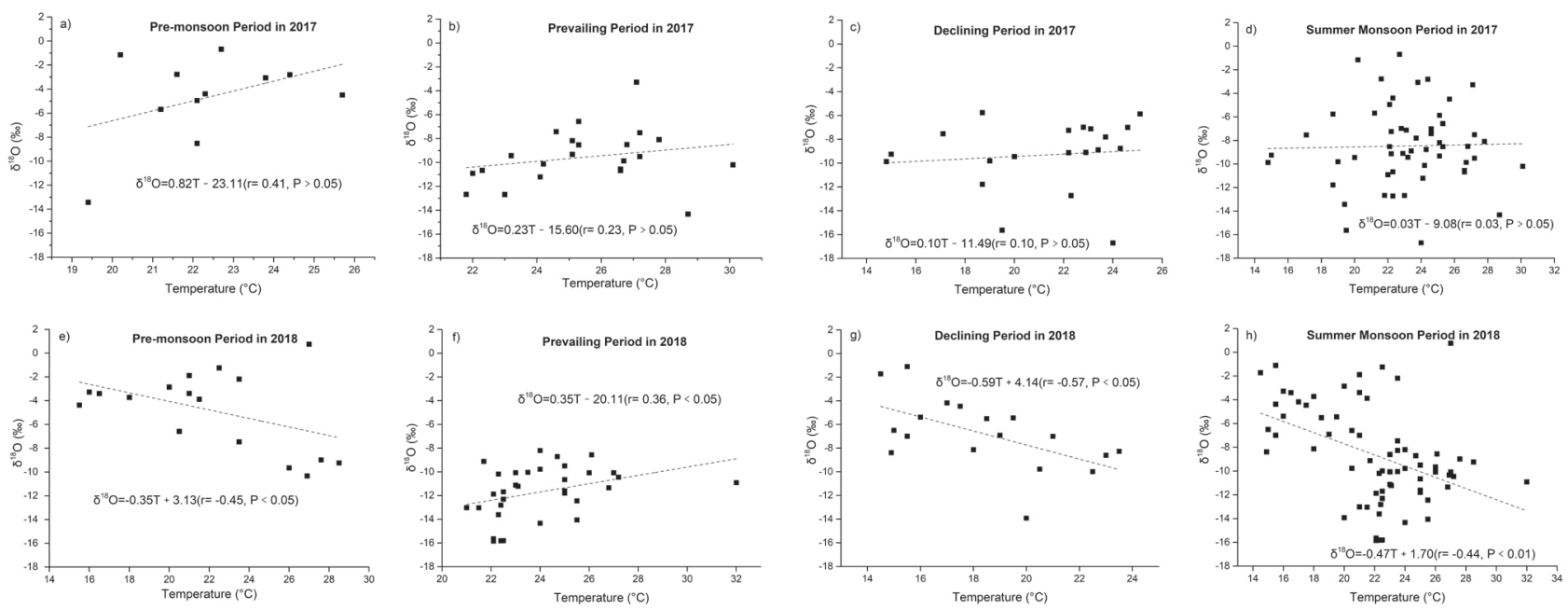

Fig. 9. Linear regressions between air temperature and $\delta 18 \mathrm{O}$ in precipitation; panels a-d) represent $\delta^{18} \mathrm{O}$-temperature (T) correlations in different periods in 2017; e-h) represent $\delta^{18} \mathrm{O}-\mathrm{T}$ correlations in different periods in 2018.

the three sub-periods $(r=0.41,0.23,0.10$ and 0.03 for pre-monsoon, prevailing, declining sub-period and entire summer monsoon period, respectively). However, none passed the significance test at the 0.05 confidence level, and none showed an obvious temperature effect. In 2018, the $\delta^{18} \mathrm{O}$ showed a significant negative correlation with temperature in the entire summer monsoon period $(\mathrm{r}=-0.44)$ and in the pre-monsoon $(r=-0.45)$ and declining $(r=-0.57)$ periods, and showed a significant positive correlation during the prevailing monsoon period $(\mathrm{r}=0.36)$. The negative correlation of $\delta^{18} \mathrm{O}-\mathrm{T}$ does not conform to the physical temperature effect and cannot reflect the response of the precipitation isotope to local temperature. This negative correlation has been observed in many areas of mid-low-latitude monsoon regions. One reason for this is the temporal change in the moisture source. However, the climatic characteristics of the same period of rain and heat cause the precipitation effect to disguise the influence of temperature on the isotopes. Chengdu is located in a subtropical monsoon climate zone and is affected by various atmospheric circulation processes during the summer monsoon, such as convection caused by monsoon activity and recycled moisture generated by surface evaporation and sub-cloud evaporation. These factors lead to complicated fractionation, mixing, and exchange processes of the isotopes in the moisture, thus masking the effect of temperature on the isotope fractionation.
In Chengdu, the relationships of $\delta^{18} \mathrm{O}-\mathrm{P}$ and $\delta^{18} \mathrm{O}-\mathrm{T}$ showed significant differences among the years and sub-periods, indicating that it is not advisable to quantitatively obtain the change information on temperature and precipitation based on precipitation isotopes. Similarly, the temporal variations in temperature and precipitation cannot be quantitatively indicated by the isotopic compositions of biological and geological proxies, which reflect the seasonal or annual accumulation characteristics of precipitation isotopes. However, the monsoon climate can be qualitatively described. The negative isotope values of ice cores, tree rings, stalagmites, and speleothems may indicate warmer climates and more precipitation as well as a greater contribution of ocean moisture to precipitation.

\section{Conclusions}

This study reported the measured data of precipitation isotopes in the summer monsoon period of 2017 and 2018 and presented the variation characteristics and influencing factors of stable isotopes in the summer monsoon precipitation in Chengdu. Our results showed that the precipitation events exhibited significant differences in isotope values, d-excess and LMWLs between different sub-periods because of the monsoon activities. For most precipitation events, the source information estimated by d-excess and 
$\delta^{18} \mathrm{O}$ were consistent with the air mass information generated by HYSPLIT. Generally, the precipitation caused by moisture from ocean-source air masses had low d-excess values and negative $\delta^{18} \mathrm{O}$, and that caused by moisture derived from dry air masses from inland sources had high d-excess values and less negative $\delta^{18} \mathrm{O}$. However, for some precipitation events, the influence of other factors led the correlation between the isotope composition and the water vapor source to be more complicated. The $\delta^{18} \mathrm{O}-\mathrm{P}$ and $\delta^{18} \mathrm{O}-\mathrm{T}$ correlation changed significantly between years and sub-periods within a year and were closely related to moisture sources and meteorological conditions. The isotope information in precipitation and biological and geological proxies can be used as a comprehensive indication of monsoon activities but cannot reflect the changes in temperature and precipitation quantitatively. However, in this study, other factors that may cause isotope changes have not been fully recorded. The differences in $\delta \mathrm{D}$ and $\delta^{18} \mathrm{O}$ between Chengdu and its surrounding area were not presented and the spatial diversity of precipitation stable isotopes was not discussed due to the limitation of only one sampling site. In future research, longterm sampling and measurement of precipitation as well as full consideration of variables that may affect isotope changes will help to more effectively interpret the monsoon information contained in precipitation isotopes and the paleoclimate information contained in isotopes in biological and geological proxies. A city scale observation network will be useful for enhancing the knowledge of spatial incoherence and synoptic processes.

\section{Acknowledgements}

This study was supported by a research project from the National Natural Science Foundation of China (No. 41471084). We would like to thank the Chengdu Public Meteorological Service Website and China Weather Network for providing meteorological data of high precision.

\section{Conflict of Interest}

The authors declare no conflict of interest.

\section{References}

1. SIEGENTHALER U. Stable Hydrogen and Oxygen Isotopes in the Water Cycle. In Lectures in Isotope Geology 264, 2011.

2. BAETA A. Stable Isotope Ecology. Encyclopedia of Ecology, 606, 2019.

3. XU Q., HOKE G.D., JING L.Z., DING L., WANG W., YANG Y. Stable isotopes of surface water acrossthe Longmenshan margin of the eastern Tibetan Plateau. Geochemistry Geophysics Geosystems, 15 (8), 3416, 2014.
4. HE Y.Q., PANG H.X., THEAKSTONE W.H., ZHANG Z.L., LU A.G., GU J. Isotopic variations in precipitation at Bangkok and their climatological significance. Hydrological Processes, 20 (13), 2873, 2006.

5. CUI B.-L., LI X.-Y. Stable isotopes reveal sources of precipitation in the Qinghai Lake Basin of the northeastern Tibetan Plateau. Science of The Total Environment, 527528, 26, 2015.

6. HAO S., LI F., LI Y., GU C., ZHANG Q., QIAO Y., JIAO L., ZHU N. Stable isotope evidence for identifying the recharge mechanisms of precipitation, surface water, and groundwater in the Ebinur Lake basin. Science of The Total Environment, 657, 1041, 2019.

7. RICHARDS L.A., MAGNONE D., BOYCE A.J., CASANUEVA-MARENCO M.J., VAN DONGEN B.E., BALLENTINE C.J., POLYA D.A. Delineating sources of groundwater recharge in an arsenic-affected Holocene aquifer in Cambodia using stable isotope-based mixing models. Journal of Hydrology, 557, 321, 2018.

8. JOSHI S.K., RAI S.P., SINHA R., GUPTA S., DENSMORE A.L., RAWAT Y.S., SHEKHAR S. Tracing groundwater recharge sources in the northwestern Indian alluvial aquifer using water isotopes $\left(\delta^{18} \mathrm{O}, \delta^{2} \mathrm{H}\right.$ and $\left.3 \mathrm{H}\right)$. Journal of Hydrology, 559, 835, 2018.

9. CUI B.-L., LI X.-Y. Runoff processes in the Qinghai Lake Basin, Northeast Qinghai-Tibet Plateau, China: Insights from stable isotope and hydrochemistry. Quaternary International, 380-381, 123, 2015.

10. ARAGUAS-ARAGUAS L., FROEHLICH K., ROZANSKI K. Stable isotope composition of precipitation over southeast Asia. Journal Of Geophysical ResearchAtmospheres, 103 (D22), 28721, 1998.

11. ASRAT A., BAKER A., HELLSTROM J., MARIETHOZ G., BOOMER I., YU D., JEX C.N., GUNN J. Paleoclimate change in Ethiopia around the last interglacial derived from annually-resolved stalagmite evidence. Quaternary Science Reviews, 202, 197, 2018.

12. SURIĆ M., LONČARIĆ R., BOČIĆ N., LONČAR N., BUZJAK N. Monitoring of selected caves as a prerequisite for the speleothem-based reconstruction of the Quaternary environment in Croatia. Quaternary International, 494, 263, 2018.

13. CHENG H., EDWARDS R.L., SINHA A., SPOTL C., YI L., CHEN S.T., KELLY M., KATHAYAT G., WANG X.F., LI X.L., ZHANG H. W. The Asian monsoon over the past 640,000 years and ice age terminations. Nature, $\mathbf{5 3 4}$ (7609), 640, 2016.

14. LI Q.A., NAKATSUKA T., KAWAMURA K., LIU Y., SONG H.M. Regional hydroclimate and precipitation delta $\mathrm{O}-18$ revealed in tree-ring cellulose delta O-18 from different tree species in semi-arid Northern China. Chemical Geology, 282 (1-2), 19, 2011.

15. MA Y., FAN M., LU Y., LIU H., ZHANG S., LIU X. Stable isotope record of middle Eocene summer monsoon and its instability in eastern China. Global and Planetary Change, 175, 103, 2019.

16. CRAIG H. Isotopic Variations In Meteoric Waters. Science, 133 (346), 1702, 1961

17. DANSGAARD W. Stable Isotopes In Precipitation. Tellus, 16 (4), 436, 1964.

18. LIU Z.F., TIAN L.D., YAO T.D., CHAI X.R. spatial distribution of $\delta^{18} \mathrm{O}$ inprecipitation over China. Chinese Science Bulletin, 54 (6), 807, 2009.

19. CHEN F.L., ZHANG M.J., WANG S.J., QIU X., DU M.X. Environmental controls on stable isotopes of precipitation 
in Lanzhou, China: An enhanced network at city scale. Science Of the Total Environment, 609, 1013, 2017.

20. WANG S.J., ZHANG M.J., CHE Y.J., ZHU X.F., LIU X.M. Influence of Below-Cloud Evaporation on Deuterium Excess in Precipitation of Arid Central Asia and Its Meteorological Controls. Journal Of Hydrometeorology, 17 (7), 1973, 2016

21. CHEN F., ZHANG M., WANG S., MA Q., ZHU X., DONG L. Relationship between sub-cloud secondary evaporation and stable isotopes in precipitation of Lanzhou and surrounding area. Quaternary International, 380-381, 68, 2015.

22. KONG Y., PANG Z. A positive altitude gradient of isotopes in the precipitation over the Tianshan Mountains: Effects of moisture recycling and sub-cloud evaporation. Journal of Hydrology, 542, 222, 2016.

23. REN W., YAO T.D., XIE S.Y. Key drivers controlling the stable isotopes in precipitation on the leeward side of the central Himalayas. Atmospheric Research, 189, 134, 2017.

24. LAWRENCE J.R., GEDZELMAN S.D., ZHANG X.P., ARNOLD R. Stable isotope ratios of rain and vapor in 1995 hurricanes. Journal Of Geophysical ResearchAtmospheres, 103 (D10), 11381, 1998.

25. RIZOU D., FLOCAS H.A., ATHANASIADIS P., BARTZOKAS A. Relationship between the Indian summer monsoon and the large-scale circulation variability over the Mediterranean. Atmospheric Research, 152, 159, 2015.

26. WU Y., JI H., WEN J., WU S.-Y., XU M., TAGLE F., HE B., DUAN W., LI J. The characteristics of regional heavy precipitation events over eastern monsoon China during 1960-2013. Global and Planetary Change, 172, 414, 2019.

27. YANG Q., MU H., GUO J., BAO X., MARTÍN J.D. Temperature and rainfall amount effects on hydrogen and oxygen stable isotope in precipitation. Quaternary International. 2019.

28. ZHAO P., TAN L., ZHANG P., WANG S., CUI B., LI D., XUE G., CHENG X. Stable Isotopic Characteristics and Influencing Factors in Precipitation in the Monsoon Marginal Region of Northern China. Atmosphere, 9 (3), 97, 2018

29. XINGGANG M., WENXIONG J., GUOFENG Z., DAN D., HANXIONG P., XIUTING X., HUIWEN G., YU Z., RUIFENG Y. Stable isotope composition of precipitation at different elevations in the monsoon marginal zone. Quaternary International, 493, 86, 2018.

30. XIA C.C., LIU G.D., MEI J., MENG Y.C., LIU W., HU Y. Characteristics of hydrogen and oxygen stable isotopes in precipitation and the environmental controls in tropical monsoon climatic zone. International Journal of Hydrogen Energy, 44 (11), 5417, 2019.

31. CAI Z.Y., TIAN L.D., BOWEN G.J. ENSO variability reflected in precipitation oxygen isotopes across the Asian Summer Monsoon region. Earth And Planetary Science Letters, 475, 25, 2017.

32. XIE L., WEI G., DENG W., ZHAO X. Daily $\delta^{18} \mathrm{O}$ and $\delta \mathrm{D}$ of precipitations from 2007 to 2009 in Guangzhou, South China: Implications for changes of moisture sources. Journal Of Hydrology, 400 (3-4), 477, 2011.

33. ZHANG W.G., MENG J.Y., LIU B., ZHANG S.C., ZHANG J., JIANG M., LV X.G. Sources of monsoon precipitation and dew assessed in a semiarid area via stable isotopes. Hydrological Processes, 31 (11), 1990, 2017.
34. QU S., CHEN X., WANG Y., SHI P., SHAN S., GOU J., JIANG P. Isotopic Characteristics of Precipitation and Origin of Moisture Sources in Hemuqiao Catchment, a Small Watershed in the Lower Reach of Yangtze River. Water. 2018.

35. LU J.M., ZHANG Q.Y., TAO S.Y., JU J.H. The onset and advance of the Asian summer monsoon. Chinese Science Bulletin, 51 (1), 80, 2006.

36. WU X.D. Stable isotope compositions for meteoric water from Chengdu and their implication of climate. Acta Geologica Sinica, 29 (1), 52, 2009.

37. ESCUDERO M., STEIN A.F., DRAXLER R.R., QUEROL X., AlASTUEY A., CASTILlO S., AVILA A. Source apportionment for African dust outbreaks over the Western Mediterranean using the HYSPLIT model. Atmospheric Research, 99 (3-4), 518, 2011.

38. WANG Y., STEIN A.F., DRAXLER R.R., DE LA ROSA J.D., ZHANG X. Global sand and dust storms in 2008: Observation and HYSPLIT model verification. Atmospheric Environment, 45 (35), 6368, 2011.

39. SU L., YUAN Z., FUNG J.C.H., LAU A.K.H. A comparison of HYSPLIT backward trajectories generated from two GDAS datasets. Science of The Total Environment, 506-507, 527, 2015.

40. HENNEMAN L.R.F., CHOIRAT C., IVEY C., CUMMISKEY K., ZIGLER C.M. Characterizing population exposure to coal emissions sources in the United States using the HyADS model. Atmospheric Environment, 203, 271, 2019.

41. ZHANG X.W. Vertical Distribution of the Transported Quantity of Material and Energy by Airflow. Desert and Oasis Meteorology, 3 (2), 1, 2009.

42. SALAMALIKIS V., ARGIRIOU A.A., DOTSIKA E. Periodicity analysis of delta $\mathrm{O}-18$ in precipitation over Central Europe: Time-frequency considerations of the isotopic "temperature" effect. Journal Of Hydrology, 534, 150,2016

43. YAPP C.J. A Model for the Relationships Between Precipitation D/H Ratios And Precipitation Intensity. Journal Of Geophysical Research-Oceans, 87 ( $\mathrm{Nc12}$, 9614, 1982.

44. MERLIVAT L., JOUZEL J. Global Climatic Interpretation Of the Deuterium-Oxygen-18 Relationship for Precipitation. Journal Of Geophysical Research-Oceans, 84 ( Nc8), 5029, 1979.

45. ZHANG X.P., SUN W.Z., LIU J. M. Stable isotopes in precipitation in the vapor transport path in Kunming of Southwest China. Resources and Environment in the Yangtze Basin, 14 (5), 665, 2005.

46. ZHOU J.-L., LI T.-Y. A tentative study of the relationship between annual $\delta^{18} \mathrm{O} \& \mathrm{amp} ; \delta \mathrm{D}$ variations of precipitation and atmospheric circulations - A case from Southwest China. Quaternary International, 479, 117, 2018.

47. WU H., ZHANG X., XIAOYAN L., LI G., HUANG Y. Seasonal variations of deuterium and oxygen-18 isotopes and their response to moisture source for precipitation events in the subtropical monsoon region. Hydrological Processes, 29 (1), 90, 2015.

48. WAN H., LIU W., XING M. Isotopic composition of atmospheric precipitation and its tracing significance in the Laohequ Basin, Loess plateau, China. Science of The Total Environment, 640-641, 989, 2018.

49. XU T., SUN X., HONG H., WANG X., CUI M., LEI G., GAO L., LIU J., LONE M.A., JIANG X. Stable isotope ratios of typhoon rains in Fuzhou, Southeast China, during 2013-2017. Journal of Hydrology, 570, 445, 2019. 
50. LAWRENCE J.R., GEDZELMAN S.D. Low stable isotope ratios of tropical cyclone rains. Geophysical Research Letters, 23 (5), 527, 1996.

51. PANG H.X., HE Y.Q., LU A.G., ZHAO J.D., NING B.Y., YUAN L.L., SONG B. Synoptic-scale variation of $\delta 180$ insummer monsoon rainfall at Lijiang, China. Chinese Science Bulletin, 51 (10), 2897, 2006.

52. DENG Z.M., ZHANG X., PAN G.Y. Variations of Hydrogen and Oxygen Isotopes in Meteoric Precipitation in Wuhan, China. Journal of Yangtze River Scientific Research Institute, 33 (7), 12, 2016.

53. ZHANG X.P., GUAN H., SUN Z., SUN G.L., ZHANG X.Z., WU H. Simulations of Stable Isotopic Variations in Precipitation and Comparison with Measured Values in Yunnan Province-China. SCIENTIA GEOGRAPHICA SINICA, 32 (1), 121, 2012. 
